\title{
Metal ion-exchange on the muscovite mica surface
}

\author{
Wester de Poel ${ }^{\mathrm{a}}$, Sarah L. Vaessen ${ }^{\mathrm{a}}$, Jakub Drnec ${ }^{\mathrm{b}}$, Anthonius H.J. Engwerda ${ }^{\mathrm{a}}$, \\ Eleanor R. Townsend ${ }^{a}$, Stelian Pintea ${ }^{a, b}$, Aryan E.F. de Jong ${ }^{a, b}$, Maciej Jankowski ${ }^{b}$, \\ Alan E. Rowan ${ }^{\text {, }}$, Elias Vlieg ${ }^{\text {a,* }}$ \\ ${ }^{a}$ Radboud University, Institute for Molecules and Materials, Heyendaalseweg 135, Nijmegen, 6525AJ, The Netherlands \\ ${ }^{\mathrm{b}}$ ESRF, 71 Avenue des Martyrs, Grenoble, France
} Francesco Carlà ${ }^{b}$, Roberto Felici ${ }^{b}$, Johannes A.A.W. Elemans ${ }^{a}$, Willem J.P. van Enckevort ${ }^{a}$,

\section{A R T I C L E I N F O}

\section{Keywords:}

Muscovite mica

Ion-exchange

Atomic force microscopy

Surface X-ray Diffraction

$\mathrm{X}$-ray photoelectron spectroscopy

\begin{abstract}
A B S T R A C T
The surface potassium ions of muscovite mica were exchanged for several different metal ions from aqueous solution ( $\mathrm{Ag}, \mathrm{Ca}, \mathrm{V}, \mathrm{Mn}, \mathrm{Fe}, \mathrm{Ni}, \mathrm{Cu}, \mathrm{Zn}, \mathrm{Co}$, and $\mathrm{Cd}$ ). The surfaces were rinsed in water, dried under nitrogen atmosphere, and subsequently analysed using atomic force microscopy (AFM), X-ray photoelectron spectroscopy (XPS), and, for half the systems, surface X-ray diffraction (SXRD). XPS and SXRD confirmed the presence of the different metal ions at the muscovite mica surface, with a partial monolayer of the monovalent and divalent ions present on the surface. No counter ions from the used salts were detected. AFM revealed that $\mathrm{Ni}$-, and Fe-terminated muscovite mica surfaces were partially covered by nanoparticles, most likely consisting of metal (hydr)oxide. The exchanged ions remained on the surface after rinsing with ultra pure water three times. SXRD showed that $\mathrm{Cd}$ and $\mathrm{Ag}$ have a lower affinity for the muscovite mica surface than $\mathrm{Cu}, \mathrm{Ca}$, and $\mathrm{Mn}$.
\end{abstract}

(C) 2017 Published by Elsevier B.V.

\section{Introduction}

Muscovite mica (Fig. 1) is a naturally occurring mineral that can reach impressive dimensions ( 4 by $3 \mathrm{~m} \mathrm{[1]}$ ) and extreme flatness (atomic flatness over $1 \mathrm{~cm}^{2}$ after cleavage [2]). Muscovite mica has a wide range of applications, ranging from insulation of electronic components to an ingredient in shower gel. Research using this material is also very broad: muscovite mica can be used for obtaining self-assembled monolayers [35], as a substrate for light emitting devices [6], or as a neutron Doppler converter [7].

Several applications of muscovite mica derive from the ability to exchange the surface (potassium) ions for different metal ions or other cationic species $[8,9]$. Thus, self-assembled monolayers can be stabilized if they contain a cationic end group $[10,11]$. The surface may also be functionalized to give a high antibacterial activity by exchanging the surface ions for silver [12]. Muscovite mica can furthermore be used as a reinforcing silicate mineral filler in polymer composites, using ruthenium as a surface ion [13]. Finally, the surface ions (of muscovite mica in particular) have been shown to be able to influence the outcome of protein crystallization experiments [14,15].
In the muscovite mica bulk the occupancy of the $\mathrm{K}^{+}$ions is one, i.e. each layer along the (001) plane contains two potassium ions per unit cell. Muscovite mica is cleaved along the (001) crystal face, resulting in a surface with half the amount of potassium atoms (occupancy 0.5, Fig. 1B), to ensure charge neutrality of the surface. In case the surface potassium atoms are completely replaced by a divalent metal ion, the occupancy of the new metal ion will be a quarter, in order to preserve charge neutrality.

The ion-exchange capability of the muscovite mica surface has been widely investigated using a variety of metal ions in aqueous solution [8,10,12,13,16-18]. Ricci et al. [19] observed that the metal ion occupancy depends on the used salt concentration. The valence and radii of the metal ions used in the exchange may affect the outcome, not only because of charge neutrality preservation, but also as a result of the different coulomb interactions with the muscovite mica surface. The aim of this study is to investigate the ordering behaviour of different metal ions on the muscovite mica surface, and establish whether other constituents are present at the surface such as hydronium ions or counter ions from the salts. To this end, we have selected a large variety of different metal salts, several of which have not been studied before in

\footnotetext{
* Corresponding author.

E-mail addresses: w.depoel@science.ru.nl (W. de Poel), s.vaessen@student.science.ru.nl (S.L. Vaessen), drnec@esrf.fr (J. Drnec), a.engwerda@science.ru.nl (A.H.J. Engwerda),

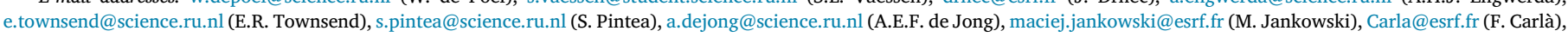

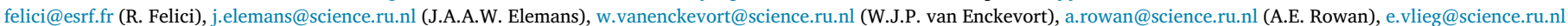
(E. Vlieg).
} 

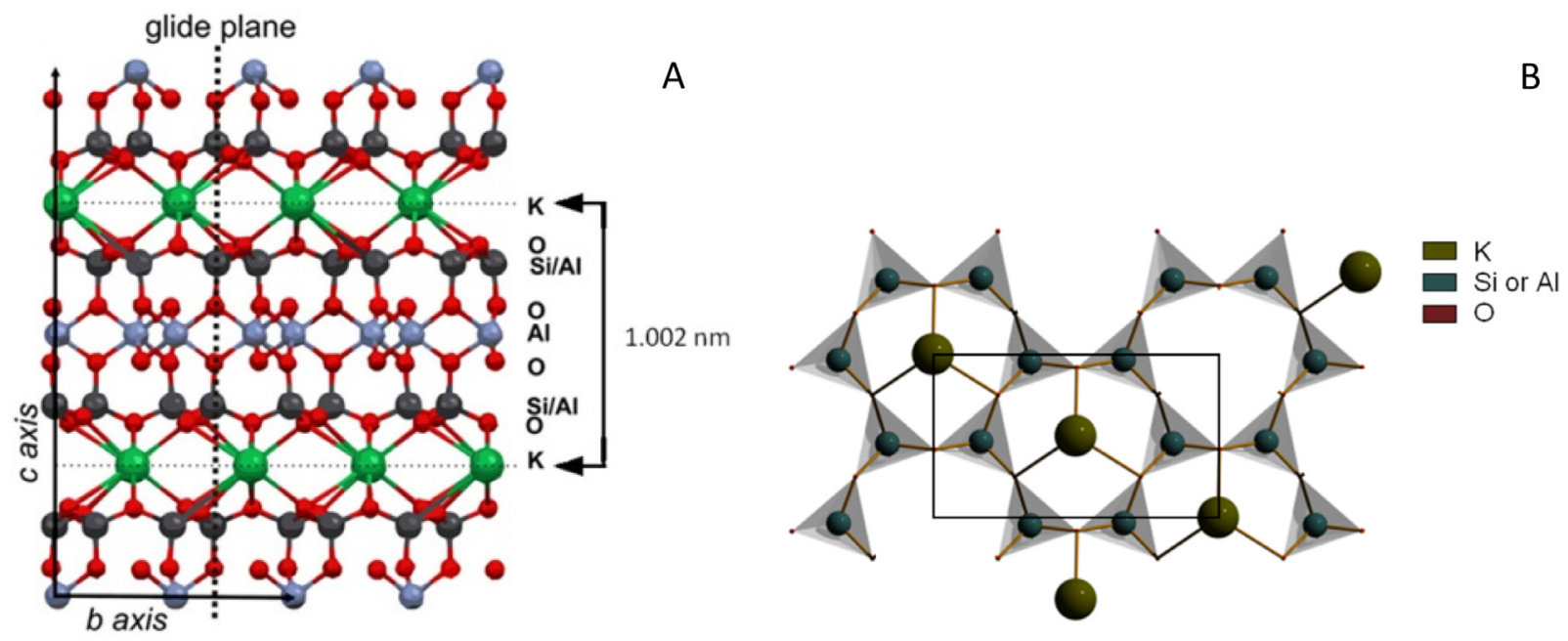

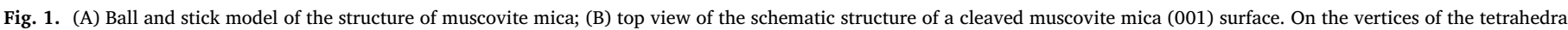

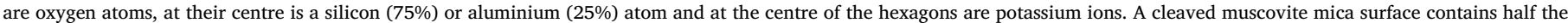
number of potassium ions as in the bulk, in order to preserve charge neutrality. The surface unit cell is indicated with the black box.

Table 1

Salts that were used for ion-exchange and their vendor.

\begin{tabular}{ll}
\hline Salt & Supplier \\
\hline Fe(II)Chloride (99\% pure) & Merck \\
V(III)Chloride (97\% pure) & Aldrich Chemistry \\
Co(II)Iodide (95\% pure) & Aldrich Chemistry \\
Ni(II)Bromide (99.99\% pure) & Sigma Aldrich \\
Mn(II)Chloride (99\% pure) & Riedel-de Haën \\
$\mathrm{Ag}(\mathrm{I})$ Nitrate (99\% pure) & Sigma Aldrich \\
$\mathrm{Ca}(\mathrm{II})$ Chloride dihydrate (99.5\% pure) & Merck \\
$\mathrm{Cd}(\mathrm{II})$ chloride hemi(pentahydrate) $(79.5-81 \%$ pure) & Sigma Aldrich \\
$\mathrm{Zn}(\mathrm{II})$ Chloride (98\% pure) & Sigma Aldrich \\
$\mathrm{Cu}(\mathrm{II})$ Chloride dihydrate (99\% pure) & Merck \\
\hline
\end{tabular}

this context, and exchanged the (001) surface potassium ions of muscovite mica using a concentration of $1 \mathrm{mM}$. We studied the dry surfaces using X-ray photoelectron spectroscopy (XPS) to investigate the chemical constituents. The surfaces were further studied using surface X-ray diffraction (SXRD), to investigate the occupancy, position, and ordering of the metal ions, which provides insight into whether different metal ions have the same or different adsorption properties under the same conditions. In addition, we also investigated the muscovite mica surfaces using atomic force microscopy, to make sure that no (salt) crystallization or other phenomena took place.

\section{Materials and methods}

\subsection{Sample preparation}

A piece of muscovite mica $(\mathrm{a}=0.51906 \mathrm{~nm}, \mathrm{~b}=0.9008 \mathrm{~nm}, \mathrm{c}=$ $2.0047 \mathrm{~nm}, \alpha=\gamma=90^{\circ}, \beta=95.757^{\circ}$, space group $C 2 / c$, chemical formula $\mathrm{KAl}_{2}\left(\mathrm{Si}_{3} \mathrm{Al} \mathrm{O}_{10}(\mathrm{OH})_{2}\right.$, quality grade ASTM-V1), obtained from S\&J Trading Inc. (Glen Oaks, NY, USA), of approximately $1 \mathrm{~cm}^{2}$ was freshly cleaved using a scalpel and put into an aqueous solution of $1 \mathrm{mM}$ of one of the salts listed in Table 1 for at least one hour for ion-exchange at $20^{\circ} \mathrm{C}$. These metals were selected because we wanted to use the metal ion-exchanged surfaces as templates for protein crystallization, the results of which will be published in a future paper [15]. The solutions were filtered prior to use with a $0.2 \mu \mathrm{m}$ pore size Whatman filter, to remove any large particles from the solution. After removal from the solution, the sample was subsequently washed three times in approximately $15 \mathrm{~mL}$ of water (ultrapure, $18.2 \mathrm{M} \Omega / \mathrm{cm}$ resistance and $<3 \mathrm{ppb}$ organic content (MQ)) for approximately $1 \mathrm{~min}$. The sample was then dried under a gentle nitrogen gas flow.

\subsection{Sample characterization}

XPS was performed at ID03 at the European Synchrotron Radiation Facility (ESRF) in Grenoble, France, using an aluminium anode as an $\mathrm{X}$-ray source of $1486.6 \mathrm{eV}$, and a hemispherical electron energy analyser with channeltron, with a resolution of $0.5 \mathrm{eV}$. In order to determine whether the detected elements are on the surface of muscovite mica and are not impurities in the bulk, XPS spectra were obtained at both a shallow angle (approximately $15^{\circ}$ ), and at a larger angle (approximately $45^{\circ}$ ). For an element at the surface, the intensity relative to a mica bulk signal should be larger at the shallow angle. The intensities of the peaks of the different metal ions were integrated, with a linear baseline correction, and normalized to the intensity of the muscovite mica $K(2 s)$ peak.

A detailed description of the SXRD experiments can be found in [3]. In short, the samples for SXRD were prepared beforehand and measured in a nitrogen atmosphere. SXRD was performed at beamline ID03 of the ESRF at $16 \mathrm{keV}$ using a Medipix area detector and a stationary measurement geometry [20]. We scanned the surface to guarantee that we collected data on a single-terminated surface, using a suitable surface reflection $\left(\begin{array}{lll}1 & 1 & 1.3\end{array}\right)$ and scanning a surface area of $5 \times 5 \mathrm{~mm}^{2}$ with a resolution of $1 \times 5 \mathrm{~mm}^{2}$ [2]. In order to fit the data to the different models, we used the ROD code [21] and applied an estimated systematic error of $10 \%$ to each data point.

Fig. 2 shows the model used to interpret the measured datasets and the free parameters used for each atom. The cavity is situated at the potassium bulk position, and contains metal ions and water/hydronium ions. The free variables for these atoms are the occupancy (occ), in-plane and out-of-plane Debye-Waller parameters $\left(\mathrm{B}_{\|}\right.$, and $\left.\mathrm{B}_{+}\right)$, out-of-plane relaxation $(\mathrm{d}(\mathrm{c})$ ), and in-plane movement $(\mathrm{d}(\mathrm{a})$ ). Above the cavity position is a water shell, with variable occupancy, in-plane and out-of plane Debye-Waller parameters, out-of-plane relaxation, and radial movement $(d(a+b))$. Lastly, there is a water layer present above the hydration shell, with variable occupancy, in-plane and out-of-plane Debye-Waller parameters, and out of plane relaxation. Fit files, data files, and parameter files can be found in the supplementary information.

AFM measurements were carried out on a Dimension 3100 AFM and a NanoScope Multimode 8 AFM with HA-NC tips from NT-MDT in intermittent contact mode under ambient conditions. AFM experiments were conducted on at least three different samples for each condition. 


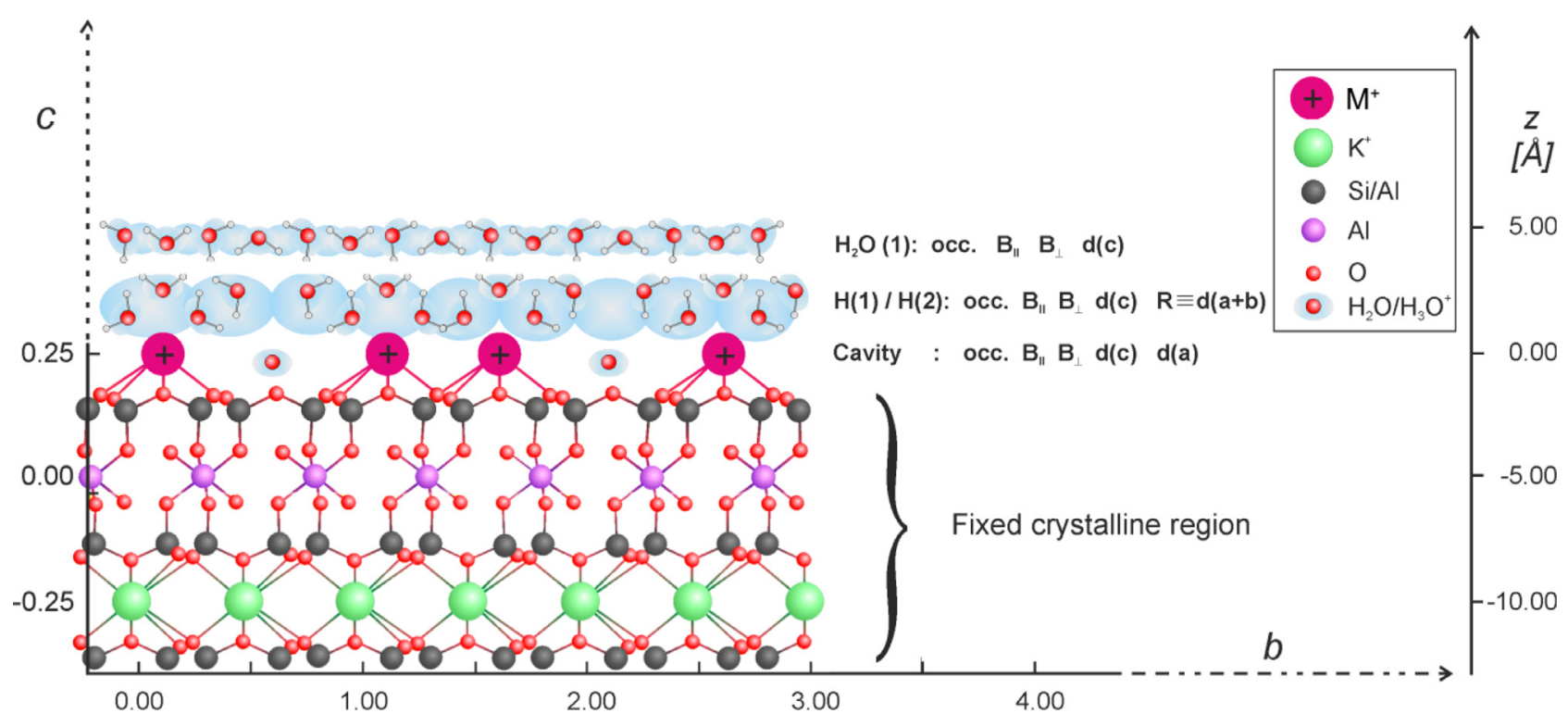

Fig. 2. Illustration of the model used to interpret the SXRD data.

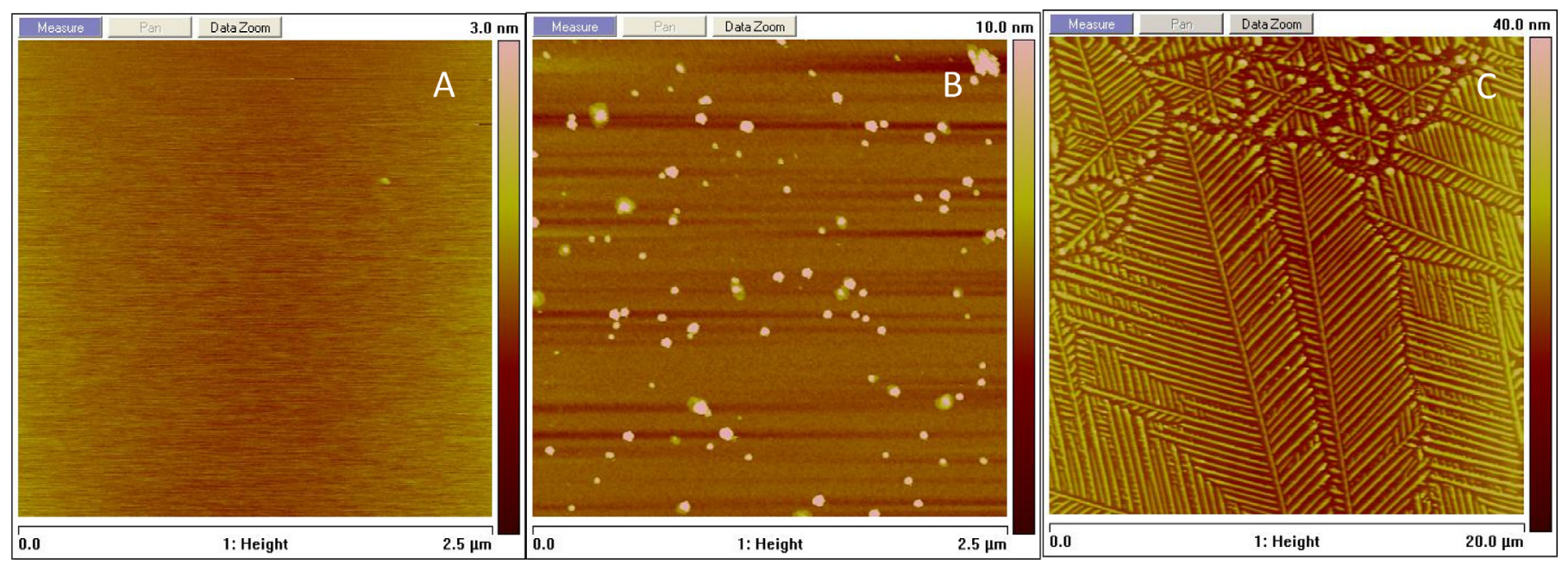

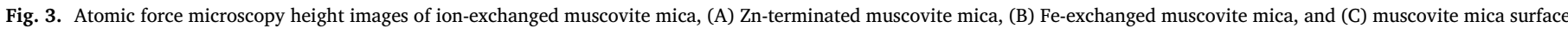
submerged in $0.1 \mathrm{M} \mathrm{KCl}$, and subsequently washed.

\section{Results and discussion}

We have investigated the metal ion-exchange of the potassium surface ions of muscovite mica for the metals listed in Table 1 using a single salt concentration in aqueous solutions. The water rinsed and dried surfaces were studied with a variety of techniques. First, AFM results will be discussed, subsequently XPS results will be presented, and lastly, SXRD experimental results will be shown.

\section{1. $A F M$}

The atomic force microscope only reveals information about the surface topology, it does not reveal whether the surface ions have exchanged. However, it does show whether 3D particles remain on the surface, i.e. if salt crystallization occurred or if the surface has remained completely flat. The flatness of the muscovite mica surface is usually not considered when ion-exchange is investigated $[8,9]$.

The solute concentration for ion-exchange was carefully selected, since too high concentrations $(0.1$ and $0.01 \mathrm{M})$ were found to provide surfaces where the salt crystallized. As an example, epitaxial $\mathrm{KCl}$ crystals were found on the surface when we used a concentration of $0.1 \mathrm{M}$
$\mathrm{KCl}$ in water (Fig. 3C), with the procedure described in the experimental section. We found that concentrations in the $\mathrm{mM}$ range are required in order to avoid salt crystallization. Fig. 3A and B show AFM images of the two measured extremes in terms of surface roughness of the surfaces obtained after the ion-exchange procedure using the $1 \mathrm{mM}$ concentration. Fig. $3 \mathrm{~A}$ shows the $\mathrm{ZnCl}_{2}$ treated surface, which is as flat as the surface of cleaved muscovite mica. The $\mathrm{FeCl}_{2}$ treated surface depicted in Fig. 3B on the other hand shows many features, which is likely "rust" [22] that has formed on the surface. It is unlikely that the particles consist of $\mathrm{FeCl}_{2}$ because this should have been removed during the three rinsing steps using water. Iron (hydr)oxide, on the other hand, will not dissolve. AFM height images of the other ion-exchanged surfaces can be found in the supplementary information (SI-1), these surfaces are either completely flat or show features that are smaller compared to the Fe-exchanged muscovite surface. The AFM measurements show that particles may pose a problem if the surface needs to remain flat after ion-exchange.

\subsection{XPS}

XPS reveals that the surface ions of muscovite mica are indeed exchanged for the respective cations (Fig. 4 and SI-2). An XPS spectrum for 
Table 2

Intensity of characteristic peaks of the ion-exchanged metal ions, normalized with respect to the $\mathrm{K}$ (2s) peak.

\begin{tabular}{|c|c|c|c|}
\hline Peak measured & Normalized intensityat $15^{\circ}$ & Normalized intensity at $45^{\circ}$ & Ratio $15^{\circ} / 45^{\circ}$ \\
\hline $\mathrm{Cu} 2 \mathrm{p}_{3 / 2}$ & 7000 & 1.7 & $4100^{\dagger}$ \\
\hline Ca $2 p_{3 / 2}$ & 2.6 & 1.3 & 2 \\
\hline $\operatorname{Cd} 3 d_{5 / 2}$ & 4.1 & 0.7 & 5.9 \\
\hline Co $2 \mathrm{~s}$ & 1.1 & 0.7 & 1.6 \\
\hline $\mathrm{Fe} 2 \mathrm{p}_{3 / 2}$ & 3.6 & 0.8 & 4.5 \\
\hline Mn $2 p_{3 / 2}$ & 1.3 & 0.06 & 22 \\
\hline Ni $2 p_{3 / 2}$ & 1.8 & 0.7 & 2.6 \\
\hline $\mathrm{V} 2 \mathrm{p}_{3 / 2}{ }^{*}$ & $1.2^{*}$ & $0.2^{*}$ & $6.0^{*}$ \\
\hline $\operatorname{Zn~} 2 \mathrm{p}_{3 / 2}$ & 31 & 5 & 6.2 \\
\hline $\operatorname{Ag~} 4 s$ & 0.08 & 0.03 & 2.7 \\
\hline
\end{tabular}

$\dagger$ The $\mathrm{K}(2 \mathrm{~s})$ peak is very small at the shallow angle measurement, thus the normalized value becomes large, as well as the ratio.

* Vanadium overlaps with a muscovite mica bulk peak, which makes this value less indicative of $\mathrm{V}$ being present at the surface.

$\$$ silver is normalized with respect to the $\mathrm{K} 2 \mathrm{p}_{3 / 2}$ peak, as the $\mathrm{K} 2 \mathrm{~s}$ peak overlaps with the peaks from $\mathrm{Ag} 3 \mathrm{~d}_{3 / 2}$, and $3 \mathrm{~d}_{5 / 2}$.

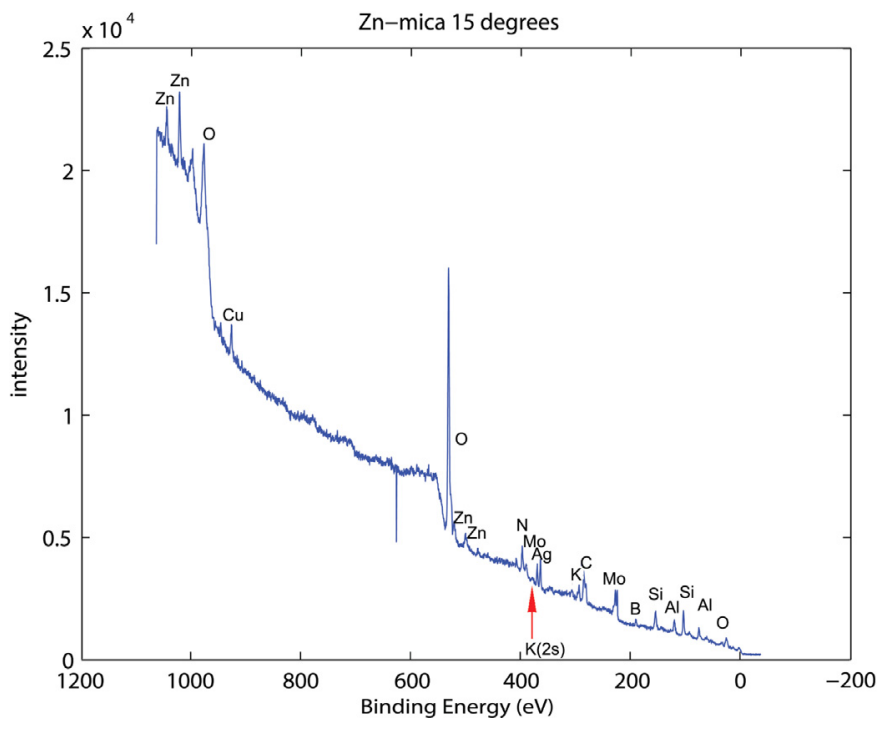

Fig. 4. XPS spectrum of Zn-terminated muscovite mica, measured with an electron exit angle of $15^{\circ}$. Mo and $\mathrm{B}$ is present in the sample holder, $\mathrm{Ag}$ is an impurity in the muscovite mica, as this peak is observed in every measurement.

Zn-terminated muscovite mica is shown in Fig. 4. Clearly distinguished peaks are visible for every exchanged surface ion in the XPS spectra (SI2), except for vanadium, as the energies of this element overlap with peak positions of the muscovite mica bulk, and except for silver, as this metal ion is a contamination in muscovite mica, and was observed in every single measurement. The vanadium ion-exchanged surface was not investigated with SXRD, so it is not possible to prove that ion-exchange occurred in this case, but the analogy with the other ions makes this very likely. The results of the XPS measurements at the two investigated angles are summarized in Table 2. This table shows that the normalized peak intensity from the metal ions on the different ion-exchanged muscovite micas increases in intensity at shallower electron exit angles, which means that the ions are located at the surface and not in the bulk.

Some salts contain a chloride counter ion, if this element is present on the surface, peaks should be found at around $200 \mathrm{eV}$, but experimentally only background intensity is observed. This means that the counter ions have been washed away. On first sight, this seems to be in conflict with the work by Pintea et al. [18], who observed that the $\mathrm{Cs}^{+}$metal counter ion, $\mathrm{Cl}^{-}$, was present at the surface of the solid-liquid interface during ion-exchange. However, in this in-situ study the muscovite mica surface
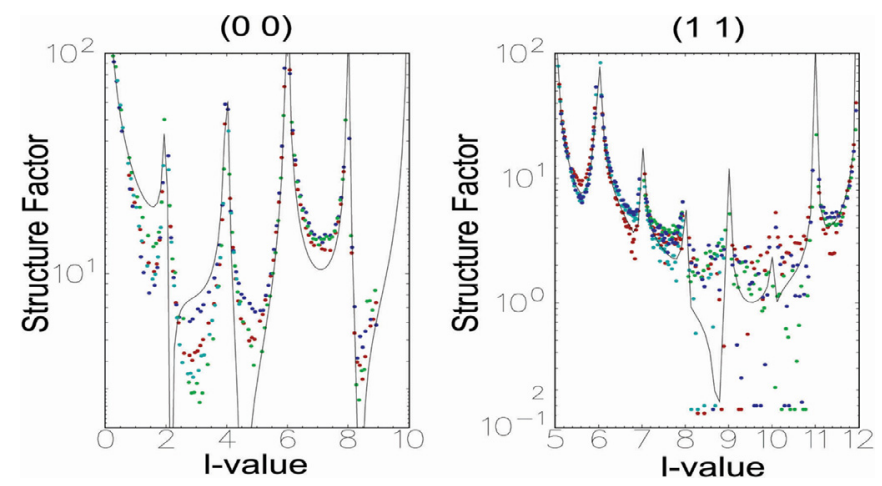

Fig. 5. SXRD data of Cu-terminated muscovite mica (cyan), Cd-terminated muscovite mica (green), Mn-terminated muscovite mica (red), and Ca-terminated muscovite mica (blue). Theoretical profile from K-terminated muscovite mica is indicated by a black line. The $\mathrm{y}$-axis depicts the structure factor amplitude and the $\mathrm{x}$-axis depicts the 1 diffraction index. The labels above each graph indicate the $\mathrm{h}$ and $\mathrm{k}$-values for the specific crystal truncation rod.

was in contact with the solution, whereas in the present ex-situ case the halide anions have been washed away.

The chemical make-up of the nanoparticles can also be investigated. The counter ion should be observed in case salt nanoparticles are present at the surface, or absent in the case that a metal (hydr)oxide has formed. The absence of a chloride signal confirms that the surface features seen in Fig. 3B and in SI-1 are not metal halide microcrystallites.

We can conclude that the potassium muscovite mica surface ions have successfully been replaced, and that no counter ions are present using this procedure. In the case of vanadium we cannot be certain of a successful metal ion-exchange.

\section{3. $S X R D$}

Large SXRD datasets, consisting of at least five different diffraction rods, were collected on $\mathrm{Ag}$-, and $\mathrm{Cu}$-terminated muscovite mica, and smaller sets on Cd-, Mn-, and Ca-terminated muscovite mica. The other ions were not investigated using SXRD. Fig. 5 shows the (00) and (20) rods to illustrate the differences between the differently terminated surfaces. Note that the SXRD data is not sensitive to the possible presence of nanoparticles since these do not contribute to the diffraction rods. Thus the surface ion-exchange can be selectively detected.

A large data set allows for a detailed analysis including the formation of hydration shells around the surface ions [18], but here we restrict ourselves to a relatively simple analysis in order to focus on the ionexchange. The data for each system was fitted using a model containing 
$(0,0)$

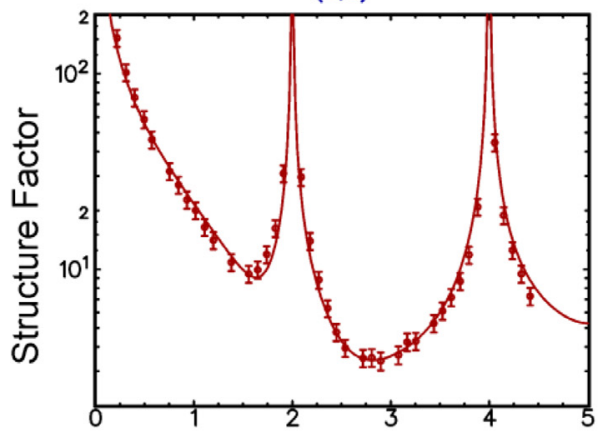

I-value

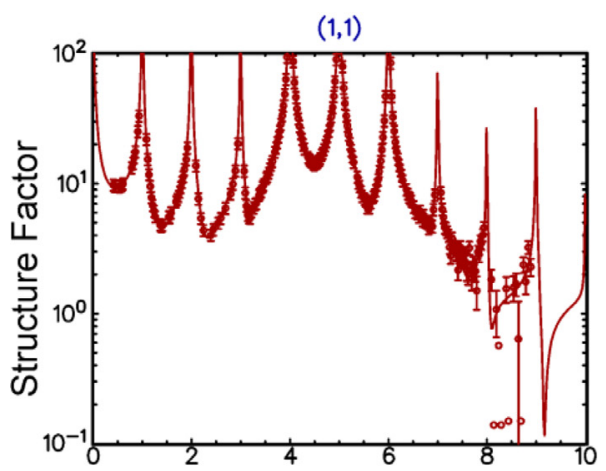

I-value

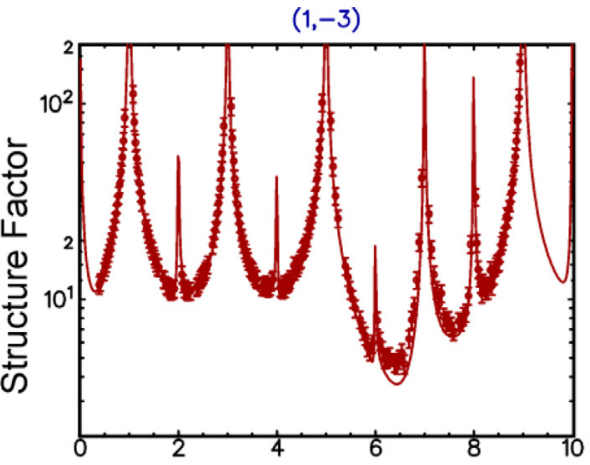

I-value

$(1,3)$

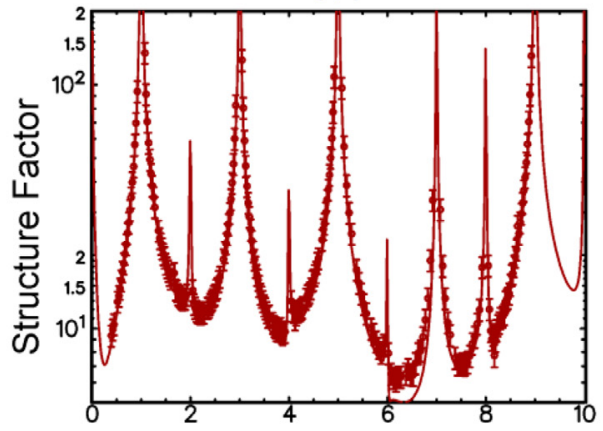

I-value

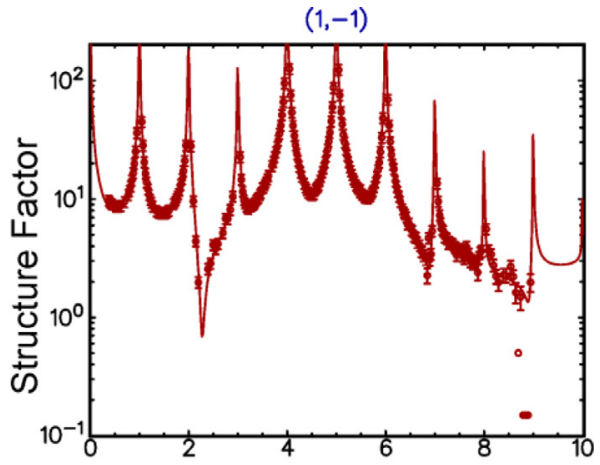

I-value

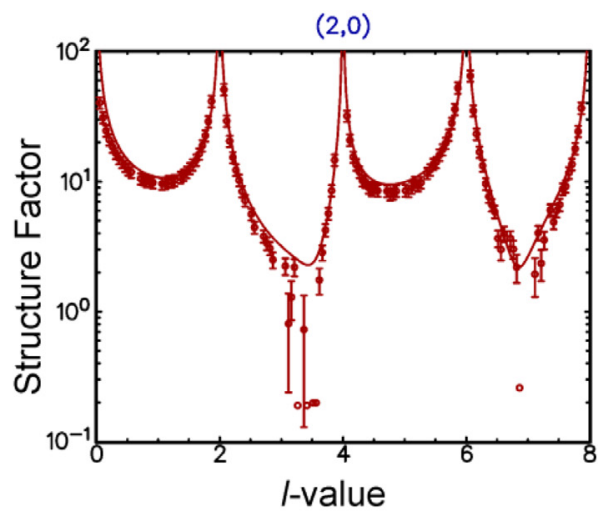

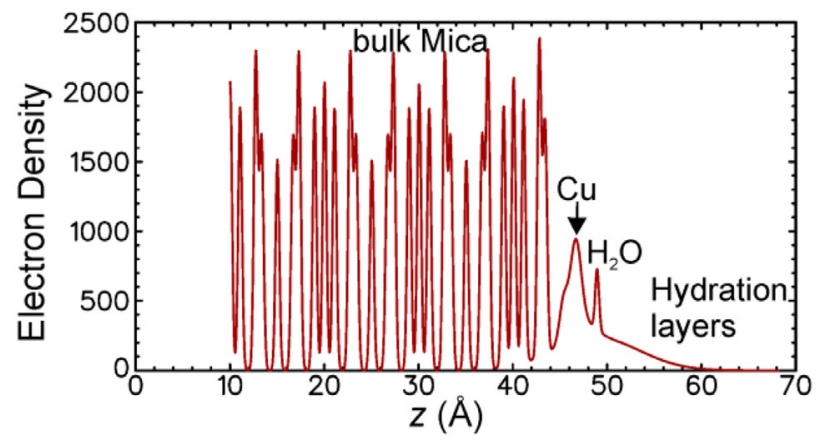

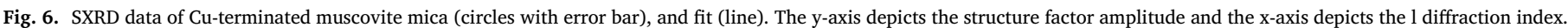
The labels above each graph indicate the $\mathrm{h}$ and $\mathrm{k}$-values for the specific crystal truncation rod. Bottom: the electron density projected on the $\mathrm{z}$-axis.

the muscovite mica bulk crystal structure, a surface with a hydration shell as used by Pintea et al. [18] and one partially ordered water layer. A thin water layer is present at the hydrophilic muscovite mica surface under ambient conditions and originates from moisture in the air. The surface ions and water molecules were allowed to move in plane and out of plane, and were given in-plane and out-of-plane Debye-Waller parameters. The occupancy of all surface atoms (i.e. metal ion and water) on top of muscovite mica surface were also free parameters. If charge neutrality of the muscovite mica surface is violated, hydronium ions are introduced at the metal site. A fit for the Cu-terminated muscovite mica dataset is shown in Fig. 6, corresponding to a $\chi^{2}$ value of 1.4. The other datasets are shown in the supplementary information SI-3, as they are very similar.

The model with a hydration shell, one water layer (indicated by $\mathrm{H}_{2} \mathrm{O}$ in the z-density plot in Fig. 6) and a partial monolayer of copper ions at the surface describe the data well. The metal ions are located at the potassium ion site of bulk muscovite mica. This is also the case for the other investigated surfaces. The occupancy parameter of the metal ions at the muscovite surface, extracted from the fit, are listed in Table 3.
Table 3

Occupancy for the different ions on muscovite mica.

\begin{tabular}{ll}
\hline Ion & Occupancy \\
\hline $\mathrm{Cu}^{2+}$ & $0,18 \pm 0,04$ \\
$\mathrm{Ca}^{2+}$ & $0,23 \pm 0,09$ \\
$\mathrm{Ag}^{+}$ & $0,28 \pm 0,03$ \\
$\mathrm{Cd}^{2+}$ & $0,09 \pm 0,05$ \\
$\mathrm{Mn}^{2+}$ & $0,32 \pm 0,04$ \\
\hline
\end{tabular}

For the cases of $\mathrm{Cu}^{2+}, \mathrm{Ca}^{2+}$, and $\mathrm{Mn}^{2+}$, the occupancies are about one quarter as expected on the basis of charge neutrality. For two ions the occupancy is significantly less than expected; $\mathrm{Cd}^{2+}$ (expected occupancy of 0.25 ), and $\mathrm{Ag}^{+}$(expected occupancy 0.5). The muscovite mica therefore, has a lower affinity with these ions, with respect to $\mathrm{Cu}^{2+}, \mathrm{Ca}^{2+}$, and $\mathrm{Mn}^{2+}$. Hydronium ions have to be present at the muscovite mica surface in order to satisfy charge neutrality.

The position of the metal ions was consistently found to be at the bulk position of $\mathrm{K}^{+}$, save for some out-of-plane relaxation. From the coverage 
of the $\mathrm{Ag}^{+}$, and $\mathrm{Cd}^{2+}$ metal ions it is clear that a $1 \mathrm{mM}$ concentration is not always sufficient for optimal coverage (which is a half and a quarter monolayer, respectively). Adjusting the concentration of the used salts will allow for optimal coverage. Furthermore, ion-exchange followed by washing with water might result in the exchange of the surface metal ions for hydronium ions.

The combination of the three used techniques (AFM, XPS, and SXRD) has unambiguously shown that the ion-exchange was successful. Each technique revealed a different insight into the ion-exchange process. AFM provided the optimal salt concentration necessary to avoid salt crystallization at the muscovite surface (mM range). XPS revealed the chemical composition of the muscovite mica surface, and showed that the muscovite mica surface potassium ions were replaced, and that the metal salt counter ion was not present. Lastly, SXRD experimental results revealed the position of the ions, and their occupancy. Therefore, together these techniques provide a good picture of the metal ionexchange process.

The described route for ion-exchange can be used, contrary to the solution case [18], in cases where the metal salt counter ion should be absent, because no counter ions were detected for this route, while counter ions are present at the surface in solution [18]. This may be important in the case of self-assembled monolayer formation or crystal growth.

\section{Conclusion}

The combination of AFM, XPS and SXRD data showed that the muscovite mica potassium surface ions can be exchanged with $\mathrm{Fe}^{2+}, \mathrm{Co}^{2+}$, $\mathrm{Ni}^{2+}, \mathrm{Mn}^{2+}, \mathrm{Ag}^{+}, \mathrm{Ca}^{2+}, \mathrm{Cd}^{2+}, \mathrm{Zn}^{2+}$ and $\mathrm{Cu}^{2+}$ ions. These ions remain at the surface even after rinsing with water, while their counter ions (like $\mathrm{Cl}^{-}$) are washed away. In the case of $\mathrm{Fe}$, and $\mathrm{Ni}$ (hydr)oxide nanoparticles are present on the surface, in all other cases the mica surface is atomically smooth. These surfaces have potential for investigating protein crystal growth and as stabilizing interfaces for organic compounds in the construction of self-assembled monolayers.

\section{Acknowledgements}

AFM measurements were carried out at NanoLab Nijmegen.

This research did not receive any specific grant from funding agencies in the public, commercial, or not-for-profit sectors.

\section{Supplementary materials}

Supplementary material associated with this article can be found, in the online version, at doi:10.1016/j.susc.2017.08.013.

\section{References}

[1] P.C. Rickwood, Am. Mineral. 66 (1981) 885-907.

[2] W. De Poel, S. Pintea, J. Drnec, F. Carla, R. Felici, P. Mulder, J.A.A.W. Elemans, W.J.P. van Enckevort, A.E. Rowan, E. Vlieg, Surf. Sci. 619 (2014) 19-24.

[3] W. De Poel, et al., Langmuir 30 (2014) 12570-7.

[4] L. Kankate, F. Balzer, H. Niehus, H.G. Rubahn, J. Chem. Phys. 128 (2008).

[5] T. Akutagawa, Proc. Natil. Acad. Sci. 99 (2002) 5028-5033.

[6] C. Simbrunner, et al., Acs Nano 6 (2012) 4629-4638.

[7] M.L. Crow, Physica B 241 (1997) 110-112.

[8] M.A. Osman, W.R. Caseri, U.W. Suter, J. Colloid Interface Sci. 198 (1998) 157-163.

[9] L. Xu, M. Salmeron, Langmuir 14 (1998) 5841-5844.

[10] M.O. Geke, R.A. Shelden, W.R. Caseri, U.W. Suter, J. Colloid Interface Sci. 189 (1997) 283-287.

[11] G.M. Bowers, D.L. Bish, R.J. Kirkpatrick, Langmuir 24 (2008) 10240-10244.

[12] M. Valaskova, M. Hundakova, K.M. Kutlakova, J. Seidlerova, P. Capkova, E. Pazdziora, K. Matejova, M. Hermanek, V. Klemm, D. Rafaja, Geochimica Et Cosmochimica Acta 74 (2010) 6287-6300.

[13] M. Walti, S. Kelch, M.O. Geke, R.A. Shelden, W.R. Caseri, U.W. Suter, M. Rehahn, R. Knapp, J. Colloid Interface Sci. 189 (1997) 305-311.

[14] L.H. Sun, C.Y. Xu, F. Yu, S.X. Tao, J. Li, H. Zhou, S. Huang, L. Tang, J. Hu, J.H. He, Cryst. Growth Des. 10 (2010) 2766-2769.

[15] W. de Poel, S.L. Vaessen, J.A.A.W. Elemans, W.J.P. Van Enckevort, A.E. Rowan, E. Vlieg, (In preparation).

[16] M.A. Osman, C. Moor, W.R. Caseri, U.W. Suter, J. Colloid Interface Sci. 209 (1999) 232-239.

[17] M.A. Osman, U.W. Suter, J. Colloid Interface Sci. 224 (2000) 112-115.

[18] S. Pintea, et al., Langmuir 32 (2016) 12955-12965.

[19] M. Ricci, P. Spijker, K. Voitchovsky, Nature Commun. 5 (2014).

[20] E. Vlieg, J. Appl. Crystallogr. 30 (1997) 532-543.

[21] E. Vlieg, J. Appl. Crystallogr. 33 (2000) 401-405.

[22] K. Swaminathan, C. Subramanian, C.S. Rao, Hydrometallurgy 6 (1981) 339-346. 